\title{
Der jüdische Messias Jesus und sein jüdischer Apostel Paulus
}

\author{
Hrsg. v. Armin D. Baum, Detlef Häußer und Emmanuel L. Rehfeld
}

Der jüdische Messias Jesus und sein jüdischer Apostel Paulus

Herausgegeben von ARMIN D.BAUM, DETLEF HÄUSSER und

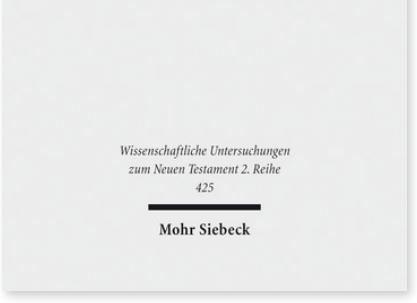

2016. VIII, 417 Seiten. WUNT II 425

ISBN 978-3-16-153873-5

DOI 10.1628/978-3-16-153873-5

eBook PDF 109,00€

ISBN 978-3-16-153872-8

fadengeheftete Broschur 109,00€
Anlässlich des 65. Geburtstags von Rainer Riesner haben sich Schüler und Kollegen zusammengefunden, um jüdische Aspekte des messianischen Wirkens von Jesus von Nazareth und des apostolischen Wirkens von Paulus von Tarsus zu beleuchten. Die Beiträge des Sammelbands kreisen mehrheitlich um die Kontinuitäten und Diskontinuitäten zwischen Judentum und Christentum, die in den neutestamentlichen Texten über Jesus und über bzw. von Paulus zu finden sind. Die Frage nach der jüdischen Verwurzelung des frühen Christentums umfasst mindestens drei Aspekte, die hier allesamt in den Blick genommen werden: das Verhältnis des Wirkens von Jesus und Paulus zu den heiligen Schriften Israels, die Beziehung von Jesus und Paulus zum zeitgenössischen Judentum und die Verknüpfung der paulinischen Theologie mit der Verkündigung Jesu bzw. der synoptischen Tradition.

Inhaltsübersicht

Thomas Pola: Zu »den Werken des Gesalbten« (Mt 11,2-6 par.) vor dem Hintergrunde der alttestamentlichen und frühjüdischen Traditionsgeschichte - Roland Deines: Der Messiasanspruch Jesu im Kontext frühjüdischer Messiaserwartungen - Emmanuel L. Rehfeld: Der Christus Israels zwischen Golgatha und Galiläa. Beobachtungen zum Verhältnis von vorösterlicher Jesusbotschaft und nachösterlichem »Christus-Kerygma« in der Darstellung der Synoptiker Armin D. Baum: Zwischen Abschreibeverhältnis und frühjüdischer Gedächtniskultur. Mclvers experimentalpsychologische Kriterien zur Identifizierung eines Abschreibeverhältnisses zwischen den synoptischen Evangelien - Volker Gäckle: Dimensionen des Heils. Die $\beta \alpha \sigma \iota \lambda \varepsilon \varepsilon^{\alpha} \alpha$ тoũ $\theta \varepsilon$ oṽ in der Verkündigung Jesu und in den Briefen des Apostels Paulus - Joe/ $R$. White: Führt der Messias sein Volk aus dem Exil? Eine kritische Auseinandersetzung mit N. T. Wrights These eines impliziten Metanarrativs hinter dem paulinischen Evangelium - Hanna Rucks: Paulus als Jude(n) lesen. Zur Auslegung von Römer 9-11 unter jesusgläubigen Juden - Guido Baltes: »Freiheit vom Gesetz« - eine paulinische Formel? Paulus zwischen jüdischem Gesetz und christlicher Freiheit - Detlef Häußer: Die Verkündigung des jüdischen Messias in der paganen Welt. Der Beitrag der Gemeinde in Philippi zur Mission des Apostels Paulus - Alexander Weiß: Paulus und die coloniae. Warum der Apostel nicht der einzige römische Bürger unter den frühen Christen war - Michael Theobald: Alt und Neu. Innovative Begriffsbildungen in den Pastoralbriefen als Indiz ihres pseudepigraphen Charakters

Armin D. Baum Geboren 1965; Professor für Neues Testament an der Freien Theologischen Hochschule Gießen, Adjunct Professor für Neues Testament an der Evangelische Theologische Faculteit Leuven (B) und Visiting Professor für Neues Testament an der Theologische Universiteit Kampen (NL).

Detlef Häußer Geboren 1968; Professor für Neues Testament an der Evangelischen Hochschule Tabor in Marburg.

Emmanuel L. Rehfeld Geboren 1980; Privatdozent für Neues Testament am Institut für Evangelische Theologie der TU Dortmund und Prediger der Landeskirchlichen Gemeinschaft Zeitz. https://orcid.org/0000-0001-5055-6187

Jetzt bestellen:

https://mohrsiebeck.com/buch/der-juedische-messias-jesus-und-sein-juedischer-apostel-paulus-9783161538735?no_cache=1 order@mohrsiebeck.com

Telefon: +49 (0)7071-923-17

Telefax: +49 (0)7071-51104 